\title{
Can probiotic cleaning solutions replace chemical disinfectants in dental clinics?
}

\author{
Farah Al-Marzooq ${ }^{1}$, Shahad Al Bayat ${ }^{2}$, Farah Sayyar ${ }^{2}$, Hamdah Ishaq ${ }^{2}$, Husain Nasralla ${ }^{2}$, \\ Rayan Koutaich², Sausan Al Kawas ${ }^{2}$
}

Correspondence: Dr. Sausan Al Kawas

Email: sausan@sharjah.ac.ae
'Sharjah Institute for Medical Research, University of Sharjah, Sharjah, UAE,

${ }^{2}$ Department of Oral and Craniofacial Health, College of Dental Medicine, University of Sharjah, Sharjah, UAE

\section{ABSTRACT}

Objectives: We aim to assess the antibacterial effectiveness of probiotic cleaning in a dental clinic at the University Dental Hospital Sharjah (UDHS), UAE. Materials and Methods: The current cleaning protocol of UDHS was evaluated by the surface swabbing of three dental clinics routinely cleaned using regular chemical disinfectants. Then, a new probiotic cleaning solution containing Bacillus subtilis was applied for 3 weeks in a selected clinic. Bacteria were grown onto selective culture media for colony counting from surfaces cleaned with probiotic solution compared to those obtained from the same surfaces cleaned with the regular chemical solutions. Isolates identity was confirmed by biochemical tests or polymerase chain reaction. Results: There was a significant reduction of the bacterial counts of various bacterial species (Staphylococci, Streptococci, and Gram-negative rods) from almost all the surfaces in the dental clinic after the application of the probiotic solution compared to the same surfaces cleaned with the regular chemical solutions. However, the antibiotic resistance rates were not significantly reduced within the short period of 3 weeks of using the new probiotic cleaning product. Conclusions: This study demonstrated that the use of probiotic cleaning is effective in reducing microbial growth in dental settings. This approach may be tested further to examine the long-term effect and to evaluate the opportunity of applying this novel biotechnology as part of the infection control routine in dental settings instead of the chemical disinfectants which are known to cause serious health problems. This is the first study testing the application of probiotic-based solution in dental settings.

Key words: Bacillus subtilis, dental settings, disinfection, infection control, probiotic

\section{INTRODUCTION}

Microbes contaminating the environment of dental clinics represent a major source of transmission of healthcare-associated infections. ${ }^{[1]}$ In the dental clinics, infections can be acquired through the aerosols, blood, saliva, and respiratory secretions. Organisms residing in the oral cavity or respiratory tract can be transmitted during dental practice.

\begin{tabular}{|l|l|}
\hline \multicolumn{2}{|c|}{ Access this article online } \\
\hline Quick Response Code: \\
\hline
\end{tabular}

These pathogens include, but are not limited to, Staphylococci, Streptococci, Mycobacterium tuberculosis, HIV, hepatitis viruses, and other microbes. ${ }^{[2]}$ Therefore, proper implementation of strict infection control measures is critical for both patients and dentists' safety.

This is an open access journal, and articles are distributed under the terms of the Creative Commons Attribution-NonCommercial-ShareAlike 4.0 License, which allows others to remix, tweak, and build upon the work non-commercially, as long as appropriate credit is given and the new creations are licensed under the identical terms.

For reprints contact: reprints@medknow.com

How to cite this article: Al-Marzooq F, Al Bayat S, Sayyar F, Ishaq $\mathrm{H}$, Nasralla $\mathrm{H}$, Koutaich $\mathrm{R}$, et al. Can probiotic cleaning solutions replace chemical disinfectants in dental clinics?. Eur J Dent 2018;12:532-9.

DOI: 10.4103/ejd.ejd_124_18 
As part of the routine infection control measures, cleaning of the surfaces in the dental clinic is recommended before and after treating each patient. The use of regular chemical cleaning products has adverse health effects, especially on those exposed to the chemical disinfectants very frequently, including nurses and dentists spending long hours in the clinics and being exposed to the chemical disinfectants through inhalation or direct contact with the skin or eyes. ${ }^{[3]}$ Continuous use of regular chemical disinfectants and detergents in cleaning the dental clinics may not remove all the pathogens completely. In addition, the persistent use of disinfectants may lead to the selection of drug resistant organisms "superbugs" in the environment. ${ }^{[1]}$

Recently, an innovative approach, based on biotechnology cleaning products has been adopted to eliminate the growth of several pathogens contaminating hospital surfaces. ${ }^{[4]}$ These biotechnology cleaning products contain probiotic bacteria, mostly from the Bacillus family. Bacillus subtilis is one of the commonly used Bacillus species in probiotic cleaning. It is a Gram-positive, rod-shaped bacterium, producing heat-resistant spores, and commonly found in the soil. ${ }^{[5]}$ These nonpathogenic bacteria are considered as a GRAS (generally recognized as safe) organism as they do not deemed to cause human diseases, with no impact on plants or animals. ${ }^{[6]}$ B.subtilis can produce antimicrobial components active against many dangerous pathogenic bacteria. ${ }^{[6,7]}$ Due to their safety and activity on pathogens, biotechnology products have been used in hospitals. ${ }^{[4]}$ Many studies have been conducted on the efficacy of probiotic sanitation, specifically using strains from the Bacillus family, demonstrating a significant reduction in microbial contamination with a stable effect over time. ${ }^{[1,8]}$ These studies were conducted in medical hospitals; however, probiotic cleaning in dental clinics was not investigated previously.

The growth of nosocomial pathogens on different surfaces of the dental clinics has been documented in many studies, whereby ordinary chemical disinfectants were used to clean different surfaces. ${ }^{[9,10]}$ In our study, we aimed to test the antibacterial effect of a probiotic solution on the pathogens in different parts of a dental clinic at a University Dental Hospital in Sharjah (UDHS), UAE, compared to regular chemical disinfectants being used in routine infection control guidelines at the same hospital.

\section{MATERIALS AND METHODS}

\section{Study setup}

This study was conducted at the UDHS, Sharjah, UAE, from February to May 2017. Dental clinics are routinely cleaned using regular chemical cleaning solutions. The floor is routinely cleaned with a chemical solution containing sodium lauryl ether sulfate and diethanolamide every day. Dental surfaces not covered by barriers are usually sterilized with a commercial disinfectant containing ethanol, 1-propanol, and quaternary ammonium compounds before and after treating each patient.

Swabs were collected from 11 sites in the dental clinics, including:

A: Floor:

A1: Floor at the side of the dental chair

A2: Floor below spittoon

B: The keyboard inside the clinic

C: Spittoon

D: Patients head rest (hidden area between the headrest and back of the dental chair)

E: Sides of patients' chair

F: Dentist chair:

F1: Back of the dentist chair

F2: Junction of back and seat

G: Drainage

$\mathrm{H}$ : Wires of handpieces

I: Around the sink for handwashing.

Surface swabbing was done in three selected dental clinics cleaned using regular chemical cleaning solutions. Two sterile swabs were collected from each of the 11 sites for 3 consecutive days at exactly the same time $(12 \mathrm{pm})$ per clinic ( 3 times $\times 1$ week $\times 11$ sites $\times 2$ swabs $/$ site $\times 3$ clinics $=198$ swabs $)$. Then, one clinic (with the most microbial growth) was selected for the application of the new probiotic cleaning solution, which contains bacteria from the species B. subtilis (Innu Science, Canada). The sanitization steps for each site were carried out by the same trained person in order to minimize any variations in the procedure adopted. Cleaning of all the surfaces was done at the same time in each day (4 pm). After each patient visit, the surfaces of dental chair were cleaned using the probiotic cleaning solution as part of the routine protocol in the dental hospital.

The probiotic cleaning product was applied for a total duration of 3 weeks. In the $1^{\text {st }}$ week, all surfaces were thoroughly cleaned with the product without swabbing. At the $2^{\text {nd }}$ and $3^{\text {rd }}$ week of the product application, 
swabs were collected from all the cleaned surfaces, whereby two sterile swabs were collected from each of the 11 sites for 3 consecutive days (at $12 \mathrm{pm}$ ) per week over a duration of 2 weeks ( 3 times $\times 2$ weeks $\times 11$ sites $\times 2$ swabs $/$ site $\times 1$ clinic $=132$ swabs $)$.

\section{Microbiology methods}

The swabs were spread on the surface of selective media for the purpose of colony counting and differentiation. Tryptone Soya Agar (Himedia, India) was used as a nonselective media for colony counting for the assessment of contamination level of the surfaces. Baird-Parker Agar supplemented with Egg Yolk Tellurite Emulsion (Himedia, India) was used for the isolation and enumeration of Staphylococci. HiCrome UTI Agar (Himedia, India) was used as a differential medium for Gram-negative coliforms. Mitis Salivarius Agar supplemented with 1\% potassium tellurite (Himedia, India) was used for the isolation of Streptococci, particularly oral species of Streptococcus mitis and Streptococcus salivarius.

The plates were incubated at $37^{\circ} \mathrm{C}$ for $24-48 \mathrm{~h}$ to check the microbial growth. At the end of the incubation period, colonies were counted. Representative colonies were picked from each agar plate, subcultured into a new plate, and then Gram stained and visualized under the light microscope. Identification was based on the colony color and morphology over the surfaces of selective media. Colonies of Staphylococcus aureus on Baird-Parker Agar looked gray-black shiny with opaque zone around the colony indicates coagulase positive reaction. Other species of Staphylococcus looked smaller, black or gray without any zone around the colonies. Identity of $S$. aureus was confirmed by polymerase chain reaction (PCR) for selected isolates using the primers published in the literature. ${ }^{[11]}$ Other Staphylococcus species were tested by biochemical identification for selected isolates using commercially available kits (KB004 HiStaph ${ }^{\mathrm{TM}}$ Identification Kit, Himedia, India).

Colonies of Gram-negative bacteria looked with different colors on the chromogenic UTI agar. Escherichia coli looked purple-magenta, Klebsiella pneumoniae looked blue to purple, mucoid, Pseudomonas sps. looked colorless (greenish pigment may be observed). Biochemical test kit (KB002 HiAssorted Biochemical Test Kit for Gram-negative rods, Himedia, India) was used for identification of Gram-negative rods.

For streptococci, identification was based on the ability to grow on the media "Mitis Salivarius Agar" which is selective for the oral streptococci, especially S. mitis and S. salivarius. Thus, biochemical identification was not done for these bacteria.

\section{Antibiotic susceptibility testing}

Bacteria were grown on Mueller-Hinton agar plates with the following antibiotic discs (Himedia, India): ceftriaxone $(30 \mu \mathrm{g})$, cefoxitin $(30 \mu \mathrm{g})$, cefepime $(30 \mu \mathrm{g})$, cefpodoxime $(10 \mu \mathrm{g})$, cefpodoxime/ clavulanic acid $(10 \mu \mathrm{g} / 5 \mu \mathrm{g})$, meropenem $(10 \mu \mathrm{g})$, gentamicin $(50 \mu \mathrm{g})$, ciprofloxacin $(30 \mu \mathrm{g})$, and trimethoprim/sulfamethoxazole $(1.25 / 23.75 \mu \mathrm{g})$. After overnight incubation at $37^{\circ} \mathrm{C}$, the diameters of the inhibition zones were measured to the nearest millimeters and interpreted in comparison with the standard values for Staphylococcus spp. and Enterobacteriaceae provided in the Clinical and Laboratory Standards Institute guidelines. ${ }^{[12]}$ Cefoxitin was used as a surrogate marker for the detection of methicillin resistance. ${ }^{[13]}$

\section{Statistical analysis}

Chi-square test or Fisher's exact test were used to compare antibiotic sensitivity results. Paired sample $t$-test was used to compare colony counts. All tests were two-tailed and $P<0.05$ was considered statistically significant. All statistical analyses were performed by PASW software version 18 (SPSS, Chicago, IL, USA). Reduction rates (\%) of bacterial counts were calculated as ([mean colony-forming unit (CFU) using regular cleaning-mean $\mathrm{CFU}$ using probiotic cleaning]/mean CFU using regular cleaning) * 100.

\section{RESULTS}

The growth of microbes on different surfaces in 3 clinics was accessed and the colony count was recorded. On Tryptone Soya Agar, the maximum colony count was observed on the floor at the side of the dental chair and at the drainage (mean CFU \pm SD: $240 \pm 10$ and $266.7 \pm 15.3$, respectively). Spittoon and floor below spittoon were also highly contaminated in the three clinics (mean CFU \pm SD: $159.3 \pm 35.5$ and $161.1 \pm 34$, respectively). The same results were observed on Baird-Parker Agar, whereby the floor at the side of the dental chair and drainage had the highest count (mean CFU \pm SD: $80.6 \pm 6.7$ and $64.3 \pm 7.4$, respectively). Bacterial counts on those surfaces were also high on the chromogenic UTI agar (mean CFU \pm SD: $80.6 \pm 5.9$ and $74.4 \pm 11.7$ for the floor at the side of the dental chair and drainage, respectively); however, spittoon exhibited the highest count on this media (mean CFU \pm SD: $118.0 \pm 17.1$ ) 
and also on Mitis Salivarius Agar (mean CFU \pm SD: $125.7 \pm 22.7)$. The least contaminated surfaces in all the clinics were area around the sink for handwashing and back of the dentist chair (mean $\mathrm{CFU} \leq 10$ on all media). The keyboard also gave bacterial growth on most of the tested media (mean CFU $\leq 60$ on all media).

The probiotic product was applied on all the surfaces of the clinic with most microbial growth for a duration of 3 weeks. The reduction rate (\%) of the bacterial counts on all surfaces after the application of the probiotic cleaning solution is shown in Table 1 . Figure 1 shows the bacterial counts on the surfaces cleaned with the new probiotic cleaning solution compared to regular chemical cleaning solution.

As shown in Figure 1 and Table 1 , there was significant reduction of the bacterial counts from almost all the surfaces in the dental clinic after the application of the probiotic cleaning solution. As shown in Table 1, reduction rates of mean CFU counts on all media were $<50 \%$ from spittoon (C) and keyboard (B). For the spittoon (C), no reduction was observed for Gram-negative rods on HiCrome UTI Agar and Streptococci on Mitis Salivarius Agar. For the drainage $(G)$ and floor below spittoon (A2), reduction in Staphylococci on Baird-Parker Agar was also $<50 \%$. For the area around the sink (I), reduction in Staphylococci on Baird-Parker Agar was also low; however, bacterial growth was minimal using both probiotic and regular cleaning solutions [Figure 1a]. More than $50 \%$ of the bacteria grown over the surface of Baird-Parker Agar were coagulase positive with the characteristic color of S.aureus. Identity was confirmed by PCR for 15 selected isolates. Identity of another
15 coagulase-negative staphylococci isolates was confirmed by the biochemical tests. Staphylococcus saprophyticus and Staphylococcus haemolyticus were isolated from different surfaces using both regular ( $n=3$ and 3 of each species, respectively) and probiotic cleaning solutions $(n=4$ and 2 of each species, respectively). Other Staphylococcus species were Staphylococcus hominis, Staphylococcus simulans, and Staphylococcus epidermidis ( $n=1$ each) isolated from around the sink (I), drainage (G), and floor (A1), respectively.

Table 2 provides the antibiotic resistance rate (\%) of 50 Staphylococcus strains isolated from different surfaces cleaned with each of regular and probiotic cleaning solutions.

As shown in Table 2, a higher number of Staphylococcus strains isolated from surfaces cleaned with probiotic cleaning solution were resistant to ciprofloxacin, cefpodoxime, cefepime, and meropenem. For the rest of the antibiotics, resistance rates were higher among the Staphylococcus strains isolated from the surfaces cleaned with the regular cleaning solution. However, the difference in the resistance rates of all the antibiotics was nonsignificant $(P>0.05)$ for Staphylococcus strains isolated from the surfaces cleaned with the regular cleaning solution compared to the probiotic cleaning solution.

HiCrome UTI Agar was supportive for the growth of Gram-negative rods. Biochemical identification of the bacteria with different colony size, morphology, and color revealed the detection of multiple species. Identity of $15 \mathrm{Gram}$-negative rods was confirmed by the

\begin{tabular}{|c|c|c|c|}
\hline \multirow[t]{2}{*}{ Surface } & \multicolumn{3}{|c|}{ Percentage reduction of mean CFU } \\
\hline & $\begin{array}{l}\text { Baird-Parker Agar } \\
\text { (Staphylococcus) }\end{array}$ & $\begin{array}{l}\text { HiCrome UTI Agar } \\
\text { (Gram-negative rods) }\end{array}$ & $\begin{array}{c}\text { Mitis Salivarius Agar } \\
\text { (Streptococcus) }\end{array}$ \\
\hline$\overline{\mathrm{A} 1}$ & 51.4 & 68.0 & 49.2 \\
\hline $\mathrm{A} 2$ & 27.3 & 70.3 & 54.7 \\
\hline B & 43.7 & 18.9 & 39.4 \\
\hline $\mathrm{C}$ & 44.4 & $0.0^{\#}$ & $0.0^{\#}$ \\
\hline $\mathrm{D}$ & 87.7 & 84.2 & NG \\
\hline$E$ & 55.0 & 77.4 & 75.0 \\
\hline $\mathrm{F} 1$ & 69.2 & 48.1 & 100.0 \\
\hline $\mathrm{F} 2$ & 77.1 & 58.3 & NG \\
\hline G & 38.4 & 73.7 & 67.5 \\
\hline $\mathrm{H}$ & 63.2 & 67.2 & NG \\
\hline I & 6.3 & 65.2 & NG \\
\hline
\end{tabular}

\#Heavy growth was obtained from C (spittoon) after using both probiotic and regular cleaning solutions. NG: No growth was obtained from these surfaces while using both probiotic and regular cleaning solutions thus reduction rate was 0 . CFU: Colony-forming unit 


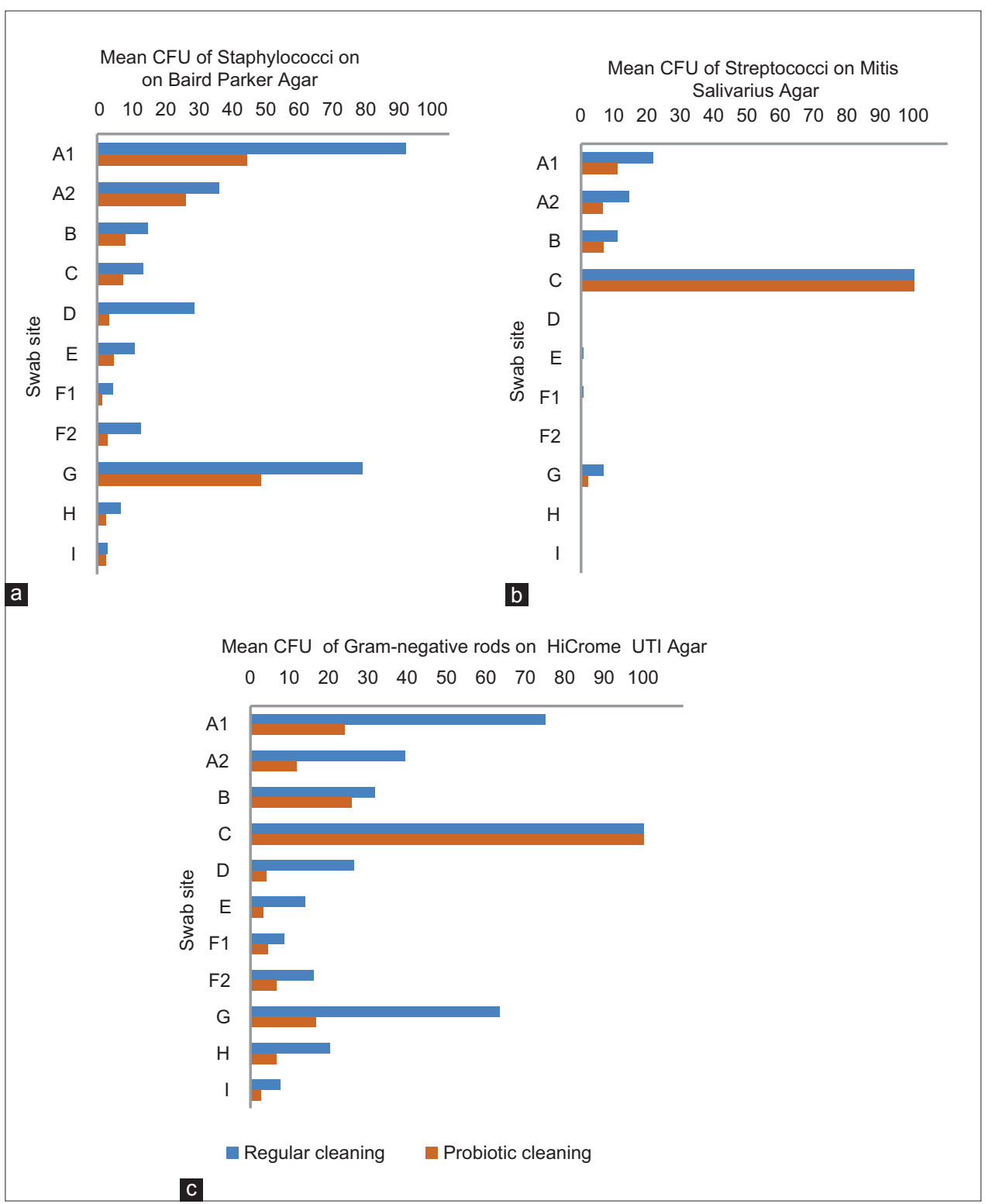

Figure 1: The effect of the new probiotic cleaning compared to the regular cleaning solutions on the growth of Staphylococci on Baird-Parker Agar (a), Streptococci on mitis salivarius agar (b), and Gram-negative rods on HiCrome UTI agar (c). Mean colony-forming unit of each bacterial species isolated from each surface is shown in the figure

biochemical tests. Bacteria with blue to purple mucoid colonies on the HiCrome UTI Agar were identified as K.pneumoniae $(n=7)$ which was recovered from different surfaces cleaned with both regular $(n=3)$ and probiotic cleaning solutions $(n=4)$. Three subspecies were identified including K.pneumoniae subsp. rhinoscleromatis $(n=4)$ recovered from the floor (A1 and A2), drainage (G), and keyboard (B), K.pneumoniae subsp. ozanae $(n=2)$ recovered from the floor (A1 and A2) and K.pneumoniae subsp. pneumoniae $(n=1)$ recovered from the spittoon $(C)$. Bacteria with colorless to yellow-green colonies on the HiCrome UTI Agar were identified as belonging to Pseudomonas species $(n=6)$, equally recovered from surfaces cleaned with both regular $(n=3)$ and probiotic cleaning solutions $(n=3)$. Four species were identified including Pseudomonas putida $(n=3)$; one recovered from the floor (A2) and two from keyboard (B), Pseudomonas luteola $(n=2)$ from the floor (A1 and A2), and Pseudomonas aeruginosa $(n=1)$ from drainage $(G)$. Bacteria with brown to purple magenta colonies on the HiCrome UTI Agar were identified as E. coli $(n=2)$, recovered from the floor (A2) and drainage $(G)$ cleaned with regular and probiotic cleaning solutions, respectively.

Of note, HiCrome UTI Agar was also supportive for the growth of $B$. subtilis present in the cleaning product 
which looked large white or blue in color based on the strain of the $B$. subtilis present in the product.

Table 3 provides the antibiotic resistance rates of 40 strains of Gram-negative rods isolated from the surfaces cleaned with the regular and probiotic cleaning solutions ( $n=20$ for each group).

As shown in Table3, a higher number of Gram-negative rods isolated from surfaces cleaned with probiotic cleaning solution were resistant to trimethoprim/ sulfamethoxazole, cefoxitin, and ceftriaxone. However, the difference in the resistance rates for these antibiotics was nonsignificant $(P>0.05)$ for strains isolated from the surfaces cleaned with the regular cleaning solution compared to the probiotic

\begin{tabular}{|c|c|c|c|}
\hline \multirow[t]{2}{*}{ Antibiotic } & \multicolumn{2}{|c|}{ Resistance rate \% $(n)$} & \multirow[t]{2}{*}{$P$} \\
\hline & $\begin{array}{l}\text { Regular } \\
\text { cleaning } \\
(n=25)\end{array}$ & $\begin{array}{l}\text { Probiotic } \\
\text { cleaning } \\
(n=25)\end{array}$ & \\
\hline Ciprofloxacin & $16(n=4)$ & $24(n=6)$ & 0.725 \\
\hline Trimethoprim/sulfamethoxazole & $32(n=8)$ & $20(n=5)$ & 0.52 \\
\hline Cefoxitin* & $56(n=14)$ & $44(n=11)$ & 0.572 \\
\hline Ceftriaxone & $40(n=10)$ & $40(n=10)$ & 1 \\
\hline Cefpodoxime & $76(n=19)$ & $68(n=17)$ & 0.754 \\
\hline Cefepime & $24(n=6)$ & $40(n=10)$ & 0.364 \\
\hline Meropenem & $16(n=4)$ & $28(n=7)$ & 0.496 \\
\hline Gentamicin & $4(n=1)$ & 0 & 1 \\
\hline
\end{tabular}

\begin{tabular}{|c|c|c|c|}
\hline \multirow[t]{2}{*}{ Antibiotic } & \multicolumn{2}{|c|}{ Resistance rate $\%(n)$} & \multirow[t]{2}{*}{$P$} \\
\hline & $\begin{array}{l}\text { Regular } \\
\text { cleaning } \\
(n=20)\end{array}$ & $\begin{array}{l}\text { Probiotic } \\
\text { cleaning } \\
(n=20)\end{array}$ & \\
\hline Ciprofloxacin & 0 & 0 & NA \\
\hline Trimethoprim/sulfamethoxazole & 0 & $10(n=2)$ & 0.487 \\
\hline Cefoxitin & $50(n=10)$ & $70(n=14)$ & 0.197 \\
\hline Ceftriaxone & $25(n=5)$ & $35(n=7)$ & 0.731 \\
\hline Cefpodoxime & $95(n=19)$ & $90(n=18)$ & 1 \\
\hline Cefepime & $60(n=12)$ & $25(n=5)$ & $0.025^{*}$ \\
\hline Meropenem & 0 & 0 & NA \\
\hline Gentamicin & 0 & 0 & NA \\
\hline ESBL@ & $55(n=11)$ & $55(n=11)$ & 1 \\
\hline \multicolumn{4}{|c|}{$\begin{array}{l}\text { *Significant difference, @ An increase in the inhibition zone diameter of }>5 \mathrm{~mm} \\
\text { for a combination disc of cefpodoxime with clavulanic acid versus cefpodoxime } \\
\text { disc alone confirmed ESBL production. NA: Not applicable, no statistics } \\
\text { was done as all the strains were sensitive to the antibiotic tested. ESBL: } \\
\text { Extended-spectrum beta-lactamases }\end{array}$} \\
\hline
\end{tabular}

cleaning solution. For cefepime, resistance rates were significantly higher $(P<0.05)$ among the strains isolated from the surfaces cleaned with the regular cleaning solution compared to probiotic cleaning solution ( $60 \%$ and $25 \%$, respectively). None of the tested strains were resistant to ciprofloxacin, gentamicin, and meropenem. Extended-spectrum beta-lactamases production was not significantly different in strains isolated from the surfaces cleaned with the regular cleaning solution compared to probiotic cleaning solution.

\section{DISCUSSION}

New alternatives to the chemical disinfectants are biotechnology cleaning products containing environment-friendly probiotic bacteria. $B$. subtilis is one of the commonly used species in probiotic cleaning. They are nonpathogenic, ubiquitous in nature as they are found in soil, water, vegetables, and in human gut. These spore-forming bacteria are suitable for addition to eco-sustainable detergents, as the spores can stay viable in the concentrated cleansers and can produce the vegetative bacteria when diluted in water and seeded on surfaces. ${ }^{[14]}$

In this study, we have applied one of the probiotic biotechnology cleaning solutions on different surfaces in a selected dental clinic for 3 weeks. Despite the short duration of this study, we noticed significant reduction in the microbial counts on most of the tested surfaces. Our results are in agreement with recent reports indicating that probiotic-based sanitation had stronger effect on surface pathogens compared to conventional disinfectants. ${ }^{[4]}$ It is worth mentioning that previous studies were all done in medical-surgical hospitals. ${ }^{[1,8]}$ To the best of our knowledge, application of cleaning solution with probiotic bacteria in a dental hospital or clinic was not reported before our study.

The probiotic cleaning solution was effective against various bacterial species (Staphylococci, Streptococci, and Gram-negative rods), which were significantly reduced from almost all the surfaces in the dental clinic after the application of the cleaning product. It is not surprising to detect bacteria of oral origin in the dental clinic environment which are probably disseminated from the aerosol generated during different dental procedures. ${ }^{[15]}$ After contaminating the environment, transmission of these bacteria can occur through contact with contaminated surfaces such as door handles, benches, towels, and taps. ${ }^{[16]}$ Some of these bacteria represent serious risk to human health. 
methicillin-resistant S. aureus (MRSA) is a pathogenic bacteria causing wide range of infections ranging from skin infections to life-threatening pneumonia and sepsis. ${ }^{[17]}$ Some studies reported the oral carriage of S. aureus, sometimes MRSA, in healthy children and adults as well as in patients with oral diseases such as periodontitis, gingivitis, failing dental implants, and patients with acrylic dentures. ${ }^{[18]}$ Staphylococci from different species were also isolated from the oral cavity of immunocompromised patients like elderly and children with hematological malignancies and patients with rheumatoid arthritis. ${ }^{[18]}$ We have detected several Gram-negative pathogens, including K. pneumoniae, Pseudomonas, and E. coli, in different parts of the dental clinic. Some of these bacteria can exist as colonizers in the oral cavity; ${ }^{[19,20]}$ however, many of them are potentially pathogenic and responsible for various types of infections, especially nosocomial infections. ${ }^{[21]}$ Probiotic cleaning is a promising approach for the eradication of these bacteria to minimize their health risks.

In general, we did not detect any significant difference in the antibiotic resistance rates of strains isolated from the surfaces cleaned with the regular cleaning solution compared to probiotic cleaning solution. Some studies reported reduction in the antibiotic resistant bacteria after the application of probiotic-based cleaning products, but this effect probably needs long duration of application as reported in a study done in a hospital in Italy, whereby the Bacillus-based probiotic product was applied for several months. After this long duration, significant decrease in the antibiotic resistance genes was evident in the bacteria isolated from the surfaces cleaned with the probiotic product compared to the original bacteria that were existing while the same surfaces were cleaned using chemical disinfectants. ${ }^{[1]}$

We found that probiotic cleaning is better than using chemical disinfectants which usually eliminate surface pathogens immediately; however, they are ineffective in preventing recontamination and pathogens regrowth occurring within a few hours after cleaning. ${ }^{[4]}$ Another disadvantage of using chemical disinfectants is that they enhance the selection of antibiotic-resistant strains. It has been reported that long exposure of K. pneumoniae to chlorhexidine-containing disinfectants led to the development of resistance to multiple commonly used antibiotics due to the development of mutations in these bacteria. ${ }^{[22]}$
The effectiveness of probiotic cleaning and the reduction in bacterial count were mostly related to the mechanism of action of the probiotic bacteria " $B$. subtilis" in the biotechnology cleaning solution, as it can reach to hidden areas that are hard to clean. Probiotic bacteria are able to disturb biofilms that function as a shelter for other pathogens; thus, facilitate their killing and elimination from hard to reach areas. In addition, they are able to kill other bacteria by competing with them for the space and nutrients. ${ }^{\left[{ }^{2,2}\right]}$ Thus, the replacement of the pathogenic bacteria by $B$. subtilis in the cleaning product was observed obviously on HiCrome UTI Agar which allowed the growth of $B$. subtilis in addition to Gram-negative bacteria. Based on several studies, B. subtilis is well known for the ability to produce multiple compounds with antimicrobial properties. For example, bacteriocins, lantibiotics (peptide antibiotics), and lantibiotic-like peptides. ${ }^{[23,24]}$ It is possible that the antimicrobial compounds produced by the $B$. subtilis present in the probiotic cleaning product may also contribute to the killing effect observed in our study.

\section{CONCLUSIONS}

The application of probiotic cleaning solution was found effective in limiting bacterial growth in different parts of the dental clinic. They are eco-friendly; thus, they can reduce the exposure to chemical disinfectants and will reduce the selection of resistant bacteria. It is necessary to establish a new biosafety protocol in dental clinics which includes adequate disinfection of surfaces by appropriate cleaning products. The information obtained from this study can be used to develop proper interventions to improve cleaning and disinfection practices in dental institutions.

\section{Acknowledgments}

The authors would like to thank Innu Science, Middle East, Dubai, for supplying the novel probiotic cleaning solution used in the study. The authors would like to thank Mr. Steve Teasdale (Innu Science, Canada) and Mr. Ali Mohri (Innu Science, Middle East, Dubai) for sharing insights on the potential of the application of the probiotic-based biotechnology cleaning solution used in our experiments.

\section{Financial support and sponsorship}

The study was financially supported by University of Sharjah, wound healing and oral diagnosis research group grant number 150307. 


\section{Al-Marzooq, et al.: Probiotic cleaning of dental clinics}

\section{Conflicts of interest}

There are no conflicts of interest.

\section{REFERENCES}

1. Caselli E, D'Accolti M, Vandini A, Lanzoni L, Camerada MT, Coccagna $\mathrm{M}$, et al. Impact of a probiotic-based cleaning intervention on the microbiota ecosystem of the hospital surfaces: Focus on the resistome remodulation. PLoS One 2016;11:e0148857.

2. Ibrahim NK, Alwafi HA, Sangoof SO, Turkistani AK, Alattas BM. Cross-infection and infection control in dentistry: Knowledge, attitude and practice of patients attended dental clinics in King Abdulaziz university hospital, Jeddah, Saudi Arabia. J Infect Public Health 2017;10:438-45.

3. Quinn MM, Henneberger PK; National Institute for Occupational Safety and Health (NIOSH), National Occupational Research Agenda (NORA) Cleaning and Disinfecting in Healthcare Working Group, Braun B, Delclos GL, Fagan K, et al. Cleaning and disinfecting environmental surfaces in health care: Toward an integrated framework for infection and occupational illness prevention. Am J Infect Control 2015;43:424-34.

4. Caselli E. Hygiene: Microbial strategies to reduce pathogens and drug resistance in clinical settings. Microb Biotechnol 2017;10:1079-83.

5. Piggot PJ. Bacillus subtilis. In: Schaechter M, editor. Encyclopedia of Microbiology. $3^{\text {rd }}$ ed. Oxford: Academic Press; 2009. p. 45-56. Available from: https: //www.sciencedirect.com/science/article/pii/ B9780123739445000365. [Last accessed on 2017 Dec 17].

6. Westers L, Westers H, Quax WJ. Bacillus subtilis as cell factory for pharmaceutical proteins: A biotechnological approach to optimize the host organism. Biochim Biophys Acta 2004;1694:299-310.

7. Ramachandran R, Chalasani AG, Lal R, Roy U. A broad-spectrum antimicrobial activity of Bacillus subtilis RLID 12.1. ScientificWorldJournal 2014;2014:968487.

8. Vandini A, Temmerman R, Frabetti A, Caselli E, Antonioli P, Balboni PG, et al. Hard surface biocontrol in hospitals using microbial-based cleaning products. PLoS One 2014;9:e108598.

9. Khalighi HR, Bakhtiari S, Radhi A, Mortazavi H, Namazi Z, Badri S, et al. Evaluation of infection control in dental clinics: Microbial isolation. Res J Biol Sci 2012;7:112-6.

10. Umar D, Basheer B, Husain A, Baroudi K, Ahamed F, Kumar A, et al. Evaluation of bacterial contamination in a clinical environment. J Int Oral Health 2015;7:53-5.

11. Delgado S, Arroyo R, Jiménez E, Marín ML, del Campo R, Fernández L, et al. Staphylococcus epidermidis strains isolated from breast milk of women suffering infectious mastitis: Potential virulence traits and resistance to antibiotics. BMC Microbiol 2009;9:82.

12. Clinical and Laboratory Standards Institute. Performance Standards for Antimicrobial Disk Susceptibility Tests; Approved Standard. M02-A11. $7^{\text {th }}$ ed. Vol. 32. 950 West Valley Road, Suite 2500, Wayne, Pennsylvania 19087, USA: Clinical and Laboratory Standards Institute; 2012.

13. Fernandes CJ, Fernandes LA, Collignon P; Australian Group on Antimicrobial Resistance. Cefoxitin resistance as a surrogate marker for the detection of methicillin-resistant Staphylococcus aureus. J Antimicrob Chemother 2005;55:506-10.

14. Venâncio GN, Marques VH, Cestari Thiago F, de Almeida ME, da Cruz CB. Microbial contamination of a university dental clinic in Brazil. Braz J Oral Sci 2016;15:248-51.

15. Khan HA, Ahmad A, Mehboob R. Nosocomial infections and their control strategies. Asian Pac J Trop Biomed 2015;5:509-14.

16. Paterson GK, Harrison EM, Holmes MA. The emergence of mecC methicillin-resistant Staphylococcus aureus. Trends Microbiol 2014;22:42-7.

17. Smith AJ, Jackson MS, Bagg J. The ecology of Staphylococcus species in the oral cavity. J Med Microbiol 2001;50:940-6.

18. Kanazuru T, Sato EF, Nagata K, Matsui H, Watanabe K, Kasahara E, et al. Role of hydrogen generation by Klebsiella pneumoniae in the oral cavity. J Microbiol 2010;48:778-83.

19. Leão-Vasconcelos LS, Lima AB, Costa Dde M, Rocha-Vilefort LO, Oliveira AC, Gonçalves NF, et al. Enterobacteriaceae isolates from the oral cavity of workers in a Brazilian oncology hospital. Rev Inst Med Trop Sao Paulo 2015;57:121-7.

20. Gaynes R, Edwards JR, National Nosocomial Infections Surveillance System. Overview of nosocomial infections caused by gram-negative bacilli. Clin Infect Dis 2005;41:848-54.

21. Wand ME. Bacterial Resistance to Hospital Disinfection. In: Modeling the Transmission and Prevention of Infectious Disease. Springer, Cham; 2017. p. 19-54. Available from: https://www.link.springer.com/ chapter/10.1007/978-3-319-60616-3_2. [Last accessed on 2017 Dec 20].

22. Joseph B, Dhas B, Hena V, Raj J. Bacteriocin from Bacillus subtilis as a novel drug against diabetic foot ulcer bacterial pathogens. Asian Pac J Trop Biomed 2013;3:942-6.

23. Stein T. Bacillus subtilis antibiotics: Structures, syntheses and specific functions. Mol Microbiol 2005;56:845-57.

24. Rodolfi A, Caselli E. Product for Cleaning, Sanitizing and Hygienization; 2016. Available from: http:/www.google.com/patents/ WO2016170479A1. [Last accessed on 2017 Dec 31]. 